Social Cohesion, Violence, and Education in South Africa

\title{
Social Cohesion, Violence, and Education in South Africa
}

\author{
Yusuf Sayed \\ Sussex University, UK. \\ Azeem Badroodien \\ Cape Peninsula University of Technology (CPUT), Cape Town \\ Diana Rodríguez \\ Cape Peninsula University of Technology (CPUT), Cape Town. \\ Akiko Hanaya \\ Columbia University, US.
}

\begin{abstract}
Author Note
Yusuf Sayed, South African Research Chair in Teacher Education and Director: Centre for

International Teacher Education (CITE), Cape Peninsula University of Technology (CPUT),

Cape Town \& Professor In International Education and Development Policy, Centre for

International Education.
\end{abstract}

Azeem Badroodien, Associate Professor and Deputy Director: Centre for International Teacher Education (CITE).

Akiko Hanaya, Doctoral Candidate, Centre for International Education, Sussex University, UK \& Research Fellow, Centre for International Teacher Education (CITE).

Diana Rodríguez, Ed.D. Candidate at Teachers College. 


\begin{abstract}
The chapter explores how education and teachers are conceptualised within policy-making in relation to building social cohesion in South Africa. More specifically, it considers the intended educational goals of social cohesion initiatives, its value in schools in reducing societal conflict, and its objective to foster enduring forms of social justice and peace in everyday life, including counteracting gender-based violence. On the one hand, teachers play key roles in influencing the personal identities of learners, as well as the development of their values of respect and tolerance. On the other hand, their contribution is shaped by the ways in which structural inequalities, including the distribution of education opportunities, influences what they are able to do as teachers. The chapter asserts that to restore trust and build durable peace and social cohesion, and to stem violence and conflict in society, it is important to provide equal access to quality education, where teachers act as key agents of change. It is argued that education policies and programmes can contribute to greater social cohesion when they promote redistribution (equity), recognition (of diversity), representation (engagement), and reconciliation (dealing with grievances, injustice, and legacies of conflict). Through analyses of policies on social cohesion and education, and an alternative conceptualisation of violence, the chapter considers the implications of social cohesion initiatives for teachers and for the provision of equitable quality education in South Africa.
\end{abstract}

Keywords: social cohesion, violence, teachers, education policy, social justice 
Social Cohesion, Violence, and Education in South Africa

Public education institutions are arguably the primary institutions through which social solidarity in most societies may be promoted (Bellah 1973; Durkheim 1964; Merton 1968; Parsons 1967; Tawil \& Harley 2004). They are also the main sites where values and social norms can probably be best developed and where future citizens may be taught to better communicate with each other (Feinberg \& Soltis, 1998). It is also within educational institutions that engagements with past injustices, historical memory, transitional justice processes, and better communal interaction in the social arena can bring communities together and encourage processes of forgiveness and healing (Hamber, 2007).

In this chapter we examine how education and teachers are conceptualised within policy-making related to building social cohesion in South Africa. More specifically, we consider the intended educational goals of social cohesion, its value in schools in reducing societal conflict, and its objective to foster enduring forms of social justice and peace in everyday life, including counteracting gender-based violence. We argue that by providing educational opportunities to learners, teachers are the determinants both of education quality in schools (Mourshed, Chijioke, \& Barber, 2010; Sayed \& Ahmed, 2015) and of effecting nation-building, identity construction, and peace and reconciliation in classrooms. We are reminded, however, that the main drivers and symptoms of conflict and fragility in society can inevitably be traced back to structural inequalities, including the distribution of education opportunities. Thus, to stem violence and conflict, and to encourage social cohesion and peace in countries such as South Africa, we argue that it is important to provide equal access to quality education. To achieve "social justice and transformation", as espoused by Nancy Fraser (1995, p[A1]. ?[A2]), education policies and programmes need to visibly promote redistribution (equity), recognition (of diversity), representation (engagement), and 
reconciliation (dealing with grievances, injustice, and legacies of conflict). The chapter thus seeks to link policy, theory, practice and context to social cohesion.

The chapter is structured around three main threads. It begins by providing definitions of social cohesion as currently utilised in a variety of international policy documents and policies. Against this backdrop, we assert that a much more radical approach to social cohesion within the policy realm is necessary if social justice is to be actualised (Hamber \& Kelly, 2004). The second thread explores the view, as noted in the literature, that there is a close link between social injustice and inequality and violence. The chapter proposes that if the concept of peace and solidarity is to be embedded in society, a different and relational definition of violence and social cohesion is required. Lastly, for social cohesion to be a "durable configuration of social attitudes and behaviours contributing to society-wide social bonding underpinned by a particular set of institutional arrangements" (Green \& Janmaat, 2011, p. ?)[A3], the state-level components that give form to how cohesion is conceived and operationalised within state level thinking need to be better understood. In this section, we explore social cohesion in relation to education policies post-1994 that have sought to realise central values in South African education that are based on the country's constitution. We concentrate here on violence in the school environment, and examine the implications for teachers, and for the provision of quality education in South Africa.

\section{Defining Social Cohesion within Policy}

In response to increasing social inequalities, poverty and crime across the world over the past few

decades, policy-makers have begun to take a keener interest in a social cohesion agenda. Within policy documents, international organisations like the Organization for Economic Cooperation and 
Social Cohesion, Violence, and Education in South Africa

Development (OECD), the World Bank, and the United Nations Development Programme (UNDP) have conceived of and defined social cohesion in a number of ways. In each definition social cohesion is understood to be loosely concerned with bonds that bring individuals together and that influence their behaviour.

For the OECD (2011), social cohesion exists when a society ensures the "well being of all its members, fights exclusion and marginalisation, creates a sense of belonging, promotes trust, and offers its members the opportunity of upward mobility" (OECD, 2011, p. ?)[A4]. This definition suggests that social cohesion is a valuable goal in itself that contributes to maintaining long-term economic growth, and that education is a vital part of any social cohesion agenda. Social cohesion is strengthened when policies ensure that children have equal opportunities to build their human capital, regardless of socio-economic background.

The World Bank conceives of social cohesion mainly in relation to the nature and quality of relationships across people and groups in society, including the state (Marc, Willman, Aslam, Rebosio, \& Balasuriy, 2012). This view asserts that at its essence social cohesion implies a convergence across groups in society, which provides a framework within which groups can at a minimum coexist peacefully. Social cohesion is thus about the predictability of interactions across people and groups, which in turn provide incentives for collective action.

A third policy approach to social cohesion focuses on the reduction of disparities, inequalities, and social exclusion within or between societal groups in society. The UNDP (2014) conceptualises social cohesion as the strengthening of social relations, interactions, and trust within societies. In 
this characterisation, disparities and inequalities are observed to often coincide with political divisions and forms of organised violence, which are sometimes driven by long-standing grievances and collective humiliation. Social cohesion and the social contract can be mutually reinforcing, for better or worse, and thus the very process of negotiating a social contract could possibly repair damaged social cohesion. The UNDP (2014) notes that as social cohesion affects the quality and durability of the social contract, a "nascent or transitional state can make greater social cohesion a goal, that orients its contribution to the social contract" (p[A5]. ?). Understanding and respecting factors that promote or undermine social cohesion is deemed vital to advancing robust social contracts.

From these select policy frameworks, it is clear that there are multiple definitions of social cohesion, ranging from liberal to more radical perspectives. Chan, To and Chan (2006) note that this looseness of definition on the part of policy-makers means that social cohesion can sometimes be understood as equivalent to solidarity and trust, and at other times in relation to inclusion, social capital and poverty. To address this looseness, Chan et al. (2006) suggest that the concept be approached as "a state of affairs concerning both the vertical and the horizontal interactions among members of society as characterized by a set of attitudes and norms that includes trust, a sense of belonging and the willingness to participate and help, as well as their behavioural manifestations" (p[A6]. ?). They contend that a sense of belonging and a willingness to help are important requirements for the promotion of social cohesion. In part recognition of the above, the UN Department of Economic and Social Affairs (UN DESA, 2015) has in recent documents defined the socially cohesive society as one where all groups have a sense of belonging, participation, 
inclusion, recognition and legitimacy. By respecting diversity, societies are seen to harness the full potential residing in their heterogeneity.

\section{Social Cohesion and Social Justice}

For this chapter, we extend the definitions reviewed above[A7] and offer a broader approach to social cohesion. We argue that social cohesion needs to directly address those structural factors that militate against equality, especially if a (nominal) level of social justice is being sought in society. Along with Osler (2011), we assert that education focused on social cohesion needs to always equip learners with the capacity to transform society, and thus education provision needs to be constantly enriched to achieve this transformative end. In expanding this position, we draw on the work of Nancy Fraser (year[A8]?) to present a more radical conception of social cohesion one that encompasses the politics of redistribution, recognition, representation, and also reconciliation (Novelli, Lopes Cardozo, \& Smith, 2014). Such a conception moves beyond the notion of social justice as residing in the utility-maximising homo economicus individual, as evident in the work of Hayek (1944), Friedman (1962) and Bentham (1780/1988), or interpretations that consider social justice in relation to the legal and uniform interpretations of justice, thereby building on the influential work of Rawls (1971, as cited in Zwarteveen \& Boelens, 2014).

Some theories of social justice have been critiqued for failing to take into account the experiences and claims of from marginalised groups in society (Zwarteveen \& Boelens, 2014), and excluding a systematic analysis of the social, cultural and political conditions that underlie unequal distributions in the first place. Zwarteveen and Boelens (2014) assert that what is needed instead 
Social Cohesion, Violence, and Education in South Africa

is a conceptualisation of justice that is historically informed, relational and place-based in nature. Following this argument, we contend that an accent on social justice and social transformation within policy processes is critical if education is to deliver on its transformative potential. In this regard, a socially just society requires full participation as mere social interaction with others is insufficient to ensure the economic solution of redistribution of resources and opportunities. Furthermore, policies must also include socio-cultural remedies for better recognition and political representation (Fraser, 2005; also see Novelli et al., 2014) (see Figure 1 below). In expanding on Fraser's (2005) work, we argue that there is an added need for processes of reconciliation for societies affected by conflict and emerging from histories of division, and where social cohesion efforts are being particularly fortified. This addition is posited to be valuable because it would include a (paradoxical) process that both "promotes an encounter between the open expression of the painful past" and "seeks a long-term, interdependent future"(Hamber \& Kelly, 2004. p. ?)[A9]. In so doing, it deals with historic and present tensions, grievances and injustices in ways that attempt to build a more sustainable peaceful society (Fraser, 1995). 

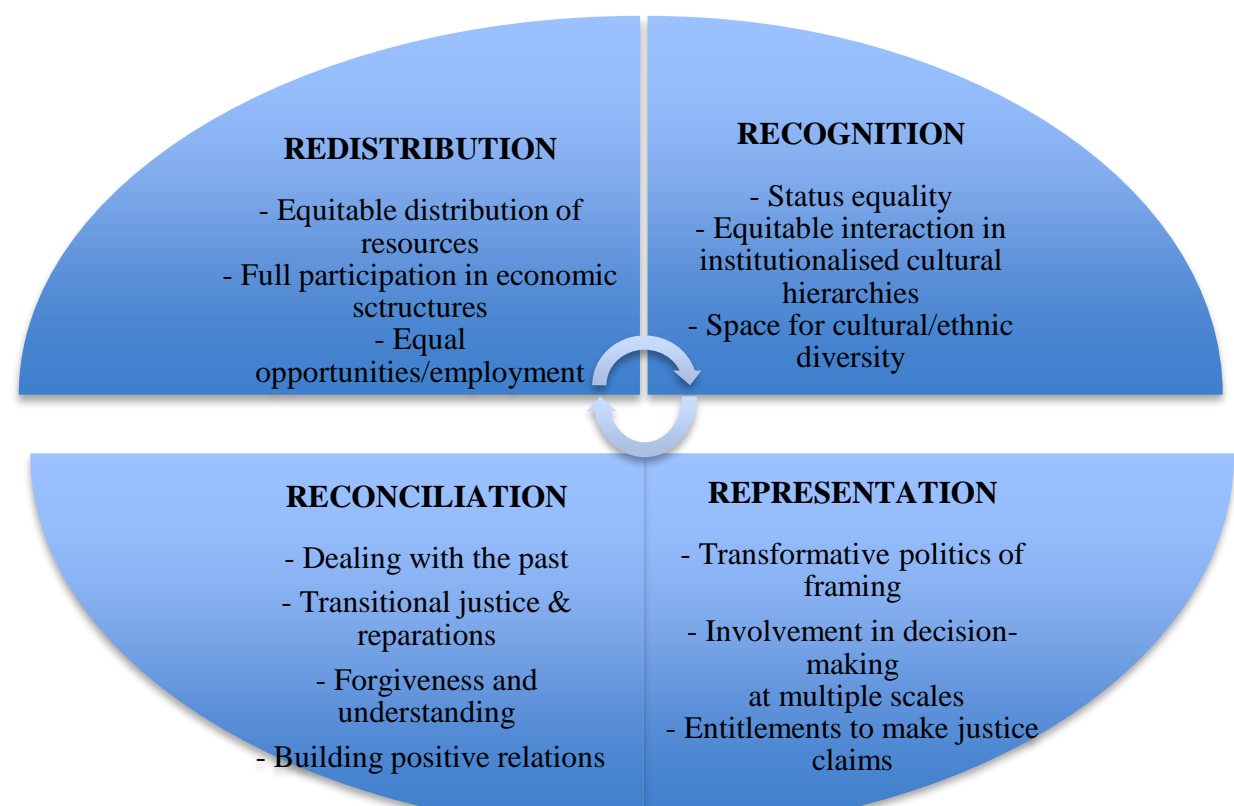

\section{REPRESENTATION}

- Transformative politics of framing

- Involvement in decisionmaking

at multiple scales

- Entitlements to make justice

claims

Figure 1. The four Rs (adapted from Fraser, 2005 \& Novelli et al., 2014)

When considered in relation to the seminal work of Galtung (1976), this conceptualisation may be likened to Galtung's reference to building positive peace, where the focus is on cultivating spaces wherein there is an "absence of structural violence, the presence of social justice, and the conditions necessary to eliminate the causes of violence" (Smith, McCandless, Paulson, \& Wheaton, 2011, p. ?)[A10]. As such, we approach education provision as playing a key role in both fostering positive peace and attempting to instil forms of justice that directly address the root causes of conflict (Keddie, 2012). We contend that by addressing injustice in and through education, especially in conflict-affected regions where socio-cultural, political and economic inequalities are often at the root of tensions and violence, greater social solidarity within societies can be fostered (also see Sayed \& Ahmed, 2015; Tikly \& Barrett 2011). 


\section{Social Cohesion and Social Justice as Counter-Narratives to Violence[A11]}

We subscribe to the view that the root of most social tensions and forms of violence in society can be found in socio-cultural, political and economic inequality. Accordingly, we interrogate: why violence is often perceived, in Comparative and International Education for example, as a pattern of fragility that reverses development (Rose \& Greeley, 2006); why scholarship in this field mainly views the concept of violence as an external, disruptive and destructive force that limits the capacity to provide access to quality services (Salmi, 2000; Seitz, 2004); and whether categorisations of violence as direct, indirect, repressive and alienating (though sometimes useful for unpacking the various elements that constitute violence) contribute to a divide between individual daily experiences of violence and broader social and political structures (Salmi, 2000)?

Drawing on the work of Scheper-Hughes and Bourgois (2004), we point to the relational dynamics of violence and its impact on social transformation. The following observations about violence are notable:

1. Violence is an interaction whereby the life chances of human individuals are hindered or destroyed, and thus violence must be seen as a series of processes of control that operate unevenly in a network of social relationships constituted in space and time.

2. Violence is a network of relationships and thus does not function in a linear or progressive manner. It is therefore never predictable.

3. Violence has the dual capacity to operate as a binding force that creates hostile personal encounters in society, as well as to impose undesired distances.

4. Violence can never be reduced to its physical dimension. It inevitably surpasses the materiality of the world to destroy individual and collective sense of dignity and worth. 
Social Cohesion, Violence, and Education in South Africa

5. Violence is never obvious, not always noisy, and certainly not self-evident. It often operates quietly through relationships of distrust, fear, paranoia and concern.

6. The mere presence of violence invariably permeates individual subjectivities, and limits the range of modalities available to integrate the physical with the emotional body.

Given that experiences of violence link individuals to broader structural arrangements, we suggest that it is through identifying the 'little' violences produced in the structures, habituses, and mentalités of everyday life that public attention can usefully be shifted to the pathologies of class, race, and gender inequalities. Scheper-Hughes and Bourgois (2004) point out that when class, race, gender, and other inequalities come together to promote social disharmony, often firmly shaped by violence, it is most acutely felt when individuals are dehumanised in the ways they interact with one another, and when institutions and societies are correspondingly structured to support this. Social disharmony is promoted when different manifestations of violence - whether that is political, structural, symbolic, or normalised violence - become intertwined in relationships between individuals and broader social and political structures and processes. This often happens without being noticed by those who experience it, contributes to the construction of an ethic of violence that regulates daily social interactions, and blinds everyone from recognising the multiple intertwining dynamics that frame the different relationships involved.

In this context, social cohesion can serve as a strong counter-narrative to violence, especially when "the total of field forces act on members to remain in the group" (Friedkin, 2004, p. 411). High levels of social cohesion can exist when interpersonal ties are characterised by feelings of trust, 
social solidarity, co-operation, and political engagement. In so doing, social cohesion can be a key means through which to transform violence.

However, this approach to social cohesion cannot be maintained unless accompanied by discernible social justice goals. Social cohesion is unlikely to embed itself within societies unless historical injustices are recognised and acknowledged and a transition from relationships of fear, distrust, embarrassment, loss and anxiety, to enriching social relationships between individuals and groups, is facilitated. We argue that in spaces where violence permeates daily life at the micro and macro level, it is the search for social justice through different types of state provisions and political engagements that would best facilitate social solidarity. In the rest of the chapter, we explore the role of education policy, education provision, and teachers (as one such provision) in building this kind of environment.

\section{Education Policies and Social Cohesion}

Having[A12] argued for a relational definition of violence and social cohesion above, and emphasised social justice as an indispensable component of peacebuilding efforts, a critical question is how we may deepen our understanding of the conflicting demands on educational institutions, and teachers as peacebuilders in protracted and post-conflict contexts.

A starting point would be to explore the implications of teaching amidst violence, and the policies attached thereto. Besides national policies, curricula, and school-level factors, we recognise that social relationships shape, constrain and challenge the daily actions of teachers in the classroom. In contexts where different forms of violence crisscross individual and collective notions of 
belonging, the role of teachers is invariably interconnected to the broader network of relationships in which they participate. As individuals, teachers are bound up in a network of social interactions that are shaped by, and shape, the context in which they work. Their capacities to engage in peacebuilding are thus constrained by the levels of violence, social cohesion and social justice within the environments in which they operate. Their capacity to engage is also influenced by the kinds of education policies and processes initiated, what the policies are meant to achieve, and what they prescribe in their operational texts.

Notably for South Africa, despite undergoing democratic elections in 1994, followed by a proliferation of education policies and a particular viewpoint of how teachers could facilitate change, meaningful change for the majority of its citizens has not been forthcoming. As such, while processes of policy development post-1994 in South Africa did try to harness social cohesion initiatives to engage with a variety of socio-economic inequalities, it is how violence became imbricated within social relationships in schools that has probably most influenced how teachers have set about fulfilling their key roles. This is explored below.

\section{Education[A13] policies and social change in South Africa after 1994}

The period 1994-1999 was arguably the most significant period in terms of policy formulation in recent South African history. This is because the period after 1994 required the development of frameworks to completely restructure the education sector and to build a unified and democratic education system that redressed past injustices. The task to inscribe in law the framework and vision of the new democratic Constitution of 1996 - 3 Green Papers, 4 White Papers, 6 Bills and 20 Acts - was immense (Sayed, Kanjee, \& Nkomo, 2013). The implied changes may be described 
Social Cohesion, Violence, and Education in South Africa

as an extreme form of "transformative remedies" to past injustices, given the focus on restructuring the underlying generative narrative of the country (Fraser, 1995, p. 86). Reforms immediately after 1994 were directed at the focus on and promotion of equality, and the eradication of all forms of discriminatory practices and structures. For example, one of the first undertakings after 1994 was to replace the previously fragmented and racially-stratified education system with a single system.

The[A14] South African Schools Act (SASA) of 1996 thereafter sought to ensure that all children had the right of access to quality education, and thus made schooling compulsory along with trying to provide an equitable allocation of state funding for education (Redistribution).

Also, redressing past injustices was one of the most articulated principles of reform, with the Constitution as well as the South African Schools Act forbidding all forms of discrimination based on race. Redress was particularly aimed at correcting past education injustices that was based on racial inequality and segregation (Reconciliation), and forbade all schools, including private schools, from using race to discriminate against learners at admission. Ironically, the act was mostly silent on how forms of discrimination affecting teachers would be addressed.

Moreover, the Constitution Section 29 (2) assured all learners the right to receive education in the official language(s) of their choice in public schools (Recognition). Broad-based participation in decision-making process was recognised as essential for the democratic movement and social change, and the SASA devolved significant powers to school governing bodies. Governing bodies were composed of the school principal and elected representatives of parents, educators, nonteaching staff and (in secondary schools) learners, and they could also co-opt non-voting members. 
Furthermore, parents were set up to have a majority stake in education governance in order to ensure that previously marginalised constituencies had a greater voice (Representation).

Finally, with regard to later education policies aimed at transformation, the Amended National Norms and Standards for School Funding and the amended South African Schools Act after 1999 sought to directly address issues of inequality in schools by recognising that funding provisions in the SASA of 1996 had worked mainly to the advantage of public schools that were patronised by middle-class and wealthy parents, and served to imitate past discriminatory investment in schooling and highlight vast disparities in the income of parents (Reconciliation). To address these inequalities, a progressive pro-poor funding policy was introduced in the period 2004-2009 where $40 \%$ of schools, namely the poorest two-fifths as determined by poverty indicators, were made 'no-fee' schools. This was extended in 2010 to include the three lowest fee quintiles.

\section{Education[A15] and the Focus on Values}

In terms of the policy process with regard to social cohesion, the most significant education policy occurred in the period 1999-2004 under Minister Kader Asmal with his Values in Education Initiative. This initiative sought to identify, realise, and embed some of the central values in South African education based on the Constitution, and led to the formation of key policies like the Manifesto on Values, Education, and Democracy of 2001 and the National Policy on Religion and Education of 2003 (Sayed et al., 2013).

The Manifesto on Values, Education and Democracy (DoE, 2001) identified key values that it felt was necessary to underpin social change and solidarity. The Manifesto identified ten fundamental 
Social Cohesion, Violence, and Education in South Africa

values (as contained in the Constitution): democracy; social justice and equity; equality; nonracism and non-sexism; Ubuntu (human dignity); an open society; accountability (responsibility); the rule of law; respect; and reconciliation, that it regarded as key to compelling social transformation. This was supported by sixteen strategic actions that was thought would help in instilling democratic values in young South Africans' in schools, which included actions such as nurturing a culture of communication and participation in schools, role modelling and promoting commitment, as well as competence among educators, making arts and culture part of the curriculum, making schools safe to learn and teach in, and ensuring the rules of law. Aware of teachers' transformative role towards social cohesion, the Manifesto denounced the many forms of violence, including sexual abuse and harassment, manifested in South African schools. To counteract this reality, the document reiterated the idea of teachers as role models. According to the Manifesto teachers had to exhibit at all times the values of competence and commitment.

To build on this, the South African History Project was also initiated shortly thereafter. One of the Project's key publications included a 6-volume series, Turning Points in South African History, in which it collaborated with the Institute for Justice and Reconciliation (IJR). The aim of the project was for it to be used in teaching South African History in the National Curriculum Statement Grades 10 - 12 (General), to lay the basis for learners to have a common outlook on the history of South Africa and about living together.

In the above policy developments, there is little doubt that many of the policies related to social cohesion said all the right things, which does not mean that the policies and their rationales were actively implemented or pursued. However, our main goal in the chapter is to sketch the trajectory 
Social Cohesion, Violence, and Education in South Africa

of policies (and their logic) associated with social cohesion as a way of locating the role assigned to education and teachers within them.

\section{Education Polices After 2009 amidst Policy Discourses of Social Cohesion}

As a concept, it was only after 2009 that the term "“social cohesion' really started to appear more frequently within official policy statements, and took a decidedly firmer form. In this regard, three policies have relevance, namely the National Development Plan (NDP) of 2012, the Mid-term Strategic Framework (MTSF) of 2014-2019, and the Department of Education's Five-year Strategic Plan (2015/16 - 2019/20).

The problem statements of each of the above documents returned to the legacies of apartheid and South Africa's divided and unequal society in terms of race, gender, disability, space, and class, and accentuated the dire need to directly address these. As such, the documents identified the Department of Arts and Culture (DAC) to be mainly responsible for coordinating this focus. In that regard, the National Strategy for Developing an Inclusive and a Cohesive South African Society (DAC, 2012) was specifically developed in 2012 to provide an overall definitional and operational view of social cohesion, captured as:

Social cohesion is defined as the degree of social integration and inclusion in communities and society at large, and the extent to which mutual solidarity finds expression itself among individuals and communities (DAC, 2012, p. 30). 
A cohesive society, according to DAC, could only be achieved if there was a reduction or elimination of inequalities and exclusions within South African society, as well as close cooperation between citizens to develop shared goals that would improve the living conditions for all.

This view, in the form of nation-building, was seen as a process whereby a society of people with diverse origins, histories, languages, cultures and religions could come together as equals within the boundaries of a sovereign state with a unified constitutional and legal dispensation, a national public education system, an integrated national economy, and shared symbols and values. The focus on a "society of people" was to work towards eradicating the divisions and injustices of the past, to foster unity, and to promote a countrywide conscious sense of being proudly South African where everyone was committed to the country, and open to the continent and the world (DAC, 2012, p. 30).

In relation to social cohesion, it was asserted that this approach to building the nation was in essence the practical actualisation of democracy based on the unity and equality of its members. Thus, while social cohesion could be thought of as community-based targeted at the micro-social level and underpinned by an overall sense of belonging, it needed to be embedded and had to operate at the national macro-level. Ironically, given the firm focus on being inclusive, the National Strategy for Developing an Inclusive and a Cohesive South African Society did not comment or elaborate on how the relationship between teachers and social cohesion was understood. 
Social Cohesion, Violence, and Education in South Africa

In this regard, the National Development Plan (NDP), in outlining the long-term macro socioeconomic policy of South Africa, devoted an entire chapter to nation-building and social cohesion (Chapter 15), stating its main target as:

A[A16] society where opportunity is not determined by race or birth right, where citizens accept that they have both rights and responsibilities, and where all seek a united, prosperous, non-racial, non-sexist and democratic South Africa.

The NDP identified the following as factors that would promote social cohesion: sport and art; interaction across race and class; learning history, heritage and culture; and learning each other's language. In pursuit of its vision, the NDP identified several actions that it felt would better achieve social cohesion in society, and within education. This included enabling learners to read the Preamble of the Constitution in different languages at school assemblies, and ensuring representation through "building integrated housing and sport facilities in communities to ensure the sharing of common spaces across race and class", and "encouraging the active participation of citizens in forums such as Integrated Development Plans, Ward Committees, School Governing Boards, and Community Policing Forums" (NDP, 2013, p. ??[A17]).

Subsequent to the above, the Mid-term Strategic Framework (MTSF) of 2014-2019 listed 14 priority outcomes that it felt would enhance nation-building and social cohesion. Outcome 14 in particular expressed the need to build "a diverse, socially cohesive society with a common national identity[A18]" (??). Outcome 1 on basic education, and Outcome 4 on employment were also conceptualised to directly support this priority. With Outcome 1, the focus on basic education 
included an initiative aimed at social cohesion with the introduction of African languages to schools. With Outcome 4, the focus was on public employment schemes, especially those that increased or added value to social cohesion initiatives.

Finally, as outlined in the MTSF, the NDP, and DAC documents, the Department of Basic Education (DBE) had historically always been seen as playing perhaps the main role in effecting social cohesion. This was most visible in the re-establishment of the Directorate for Social Cohesion and Equity in Education in 2011, which was a readjustment of the previous Directorate for Race and Values within DBE. This shift evidenced a transition to a more broad understanding of the intersections between race, class, and gender as means to social exclusion.

Moreover, the role of the DBE in the promotion of social cohesion is also visible within the DBE's long-term plan, two mid-term plans, and annual sector plans. Action Plan to 2019: Towards the Realisation of Schooling 2030, for example, details the overall direction of the basic education sector to achieve the goals set out in the NDP, in the MTSF, Five-year Strategic Plan (2015/162019/20), and in the Annual Performance Plan (2015-2016). The latter DBE plans are closely aligned to the NDP and MTSF priorities for the education sector.

This alignment is represented in Table 1 below. It highlights how the various policy papers have expressed the priority roles of education for social cohesion, and the tasks that the MSTF allocated to the DBE in achieving outcome 14 .

Table 1. Excerpts from MTSF - Tasks of the DBE for Outcome 14 


\begin{tabular}{|c|c|}
\hline Actions & Indicators \\
\hline \multirow{7}{*}{$\begin{array}{l}\text { Promote the Bill of } \\
\text { Responsibility, } \\
\text { Constitutional values and } \\
\text { national symbols amongst } \\
\text { children in schools }\end{array}$} & $\begin{array}{l}\text { National stakeholder forum established and the quarterly reporting } \\
\text { on the different roles they perform in schools }\end{array}$ \\
\hline & $\begin{array}{l}\text { Printing and distributing the Bill of Responsibilities booklets, } \\
\text { posters and flyers, together with Values in Action manuals }\end{array}$ \\
\hline & $\begin{array}{l}\text { Activities that show engagement with the Bill of Responsibilities, } \\
\text { with regions responsible for reporting }\end{array}$ \\
\hline & $\begin{array}{l}\text { Number of Learners that participate in Moot Court and other } \\
\text { Democracy Programmes }\end{array}$ \\
\hline & $\begin{array}{l}\text { Number of schools reciting the Preamble of the Constitution at } \\
\text { school assemblies }\end{array}$ \\
\hline & Percentage of schools flying the national flag \\
\hline & $\begin{array}{l}\text { Percentage of schools that have booklets and posters (Frame) of } \\
\text { national symbols and orders }\end{array}$ \\
\hline $\begin{array}{l}\text { Increase multilingualism in } \\
\text { the school environment }\end{array}$ & Percentage of schools where one African language is taught \\
\hline \multirow{3}{*}{$\begin{array}{l}\text { Promote social cohesion in } \\
\text { schools }\end{array}$} & Number of schools which offer Art \\
\hline & $\begin{array}{l}\text { Schools where oral history programme is part of the national } \\
\text { curricula }\end{array}$ \\
\hline & $\begin{array}{l}\text { Schools where National Action Plan against Racism, Xenophobia, } \\
\text { Sexism and Related Intolerances are implemented }\end{array}$ \\
\hline
\end{tabular}




\begin{tabular}{|l|l|}
\hline Provide mass participation & Mass Participation Sport events that are inclusive of social cohesion \\
opportunities & programmes \\
\hline Improve participation in & Number of programmes and interventions that focus on increasing \\
School Governing Bodies & voter turnout in schools run from the DBE \\
\cline { 2 - 2 } & Percentage of parents who participate in elections of School \\
elections & Governing Bodies \\
\hline
\end{tabular}

Furthermore, as is noted in the DBE's Five-year Strategic Plan (2015/16 - 2019/20), the term social cohesion has been used at least 12 times in relation to the introduction of African languages in schools and to other school social cohesion programmes. To operationalise this, the DBE piloted in 2014 the incremental introduction of African language (IIAL) programme in schools, as well as the drafting of a Social Cohesion Programme handbook focusing on how to improve social cohesion in schools, foster human rights and responsibilities, encourage parental and community involvement, and create a culture of excellence using local history.

This fits into the characterisation of Freemantle (2012) who notes that the fundamental characteristic of social cohesion initiatives within state policy processes is that they are mainly “integrated into an existing and long-standing discourse of nation building" (p.2) where they are used either synonymously or as an addition to nation-building. Freemantle (2012) cautions that in such a situation social cohesion would only then be seen as ways of promoting citizenship, patriotism, and nationhood, and as the main or only denominator that bonds citizens. 
Social Cohesion, Violence, and Education in South Africa

Shuayb (2012) cautions, however, that this kind of positioning in relation to nationhood rarely translates into acceptable forms of social justice. In contextualising developments within overall international trends, she notes that social cohesion initiatives in instances like that described above generally only focus on how to better foster stability and consensus when escalating inequalities are seen to threaten the economic market system. Citing Osberg (1998), Shuayb argues that using social cohesion and the building of a common citizenry in addressing inequalities can easily be seen as simply trying to develop a positive correlation between economic development and social wellbeing and as such simply be an agenda for distribution, complacency and consensus.

\section{Social Cohesion and Violence in South Africa}

Along with the ways in which social cohesion is characterised within policy documents in South Africa, as noted above, understandings of social cohesion in South African policies are also often impugned by the belief that widespread violence in schools undermines the environment necessary for effective teaching and learning. There are two approaches to this.

On the one hand, school-based violence is conceptualised in its physical manifestation and is seen to start and end in schools that socially and historically were disadvantaged. Some argue that this pervasiveness of continued violence is intimately tied to South Africa's legacy of apartheid. On the other hand, violence is also viewed within its symbolic manifestation, in its overall threat to social solidarity in South Africa. It is argued that social solidarity and community interaction is irreparably undermined when "physical violence becomes the first line strategy for resolving conflict and gaining ascendancy" (Abrahams, 2004, p. 4). 
Social Cohesion, Violence, and Education in South Africa

In South African schools, multi-dimensional school-based violence takes on various forms, such as bullying, theft, sexual and gender-based violence, assault and fighting, gang-related violence, cyber-bullying, xenophobia, corporal punishment and homophobia (Burton \& Leoschut, 2013; Mncube \& Harber, 2013). This means that students and teachers must cope with violence as a routine. Over time, its main overall consequence has been that it has changed the kinds of ways learners interact with each other and their communities. A study of the Centre for Justice and Crime Prevention, for example, found that one in five secondary school learners - a total of $22.2 \%$ - had experienced one or more form of violence while at school in the 12 months between August 2011 and August 2012 (Burton \& Leoschut, 2013). This translated to over a million secondary school learners $(1,020,597)$ across the country struggling directly with how to overcome visible conflict.

In the above regard, various treaties were ratified by South Africa from 1994 that obliged the South African government to ensure the safety of learners and educators in schools and protect their human rights. These treaties included international and regional human rights commitments attached to the Convention of the Rights of the Child (CRC, ratified in 1995), the Convention on the Elimination of All Forms of Discrimination against Women (CEDAW, ratified in 1995), the International Covenant on Civil and Political Rights (ICCPR, ratified in 1998), and the Convention Against Torture (CAT, ratified in 1998). They were further tied to regional laws and treaties dealing with violence and safety that included the African Charter on Human and Peoples' Rights (ACHPR, ratified in 1996), the African Charter on the Rights and Welfare of the Child (ACRWC, ratified in 2000), and the Protocol to the African Charter on Human and Peoples' Rights on the Rights of Women in Africa (Maputo Protocol, ratified in 2004). As such, the above treaties after 
Social Cohesion, Violence, and Education in South Africa

1994 were seemingly put in place to provide all the necessary sanctuaries to protect the rights of South African citizens.

However, a key concern with the above policies and treaties has been that they have mainly focused on protecting the human rights of learners and educators and not tried to address the psychological effects of violence and conflict on learners. This approach been mainly based on the belief that the ways learners interact with each other in schools, as well as with their communities are keenly influenced by levels of violence in their schools and communities. This is clearly evident in approaches to violence in schools, which have included:

- An Adopt-a-Cop Programme, which assigned a volunteer police officer to every participating school (1996).

- The prohibition of Corporal Punishment in schools (SASA 1997 )

- The promulgation of the Regulations for Safety Measures at all Public Schools (2001), which prohibited dangerous weapons at schools (schools declared dangerous-weapon-free zones), the possession of illegal substances, access of school property, and included safety measures for the transport of learners

- The passing of the Regulations to Prohibit Initiation Practices in Schools (2002)

- Developing a Policy Framework for the Management of Drug Abuse by Learners in Schools and in Public Further Education and Training Institutions (2002)

- Providing for Devices to be Used for Drug Testing and developing procedures to be followed (2008)

- Producing a Code of Conduct for Schools (2008) 
Social Cohesion, Violence, and Education in South Africa

- Launching the Tirisano Plan which included fostering school cultures that promoted gender equality and school safety (2008)

- Starting projects like the Department of Basic Education (DBE) and the Centre for Justice and Crime Prevention (CJCP)'s Hlayiseka ("to be safe") Project to assist schools in the early detection of crime and violence (2008)

- Initiating campaigns like the DBE's and Proudly South African Ubuntu campaign to address sexual violence and bullying at school (2012)

- Starting campaigns like the DBE and LeadSA's StopRape campaign to raise awareness about rape (2013) [A19]

As such, policies since 2008 have primarily focused on providing safe school environments. One clear example is the signing of an implementation protocol between the DBE and the South African Police Service in 2011 that "aimed to promote safer schools and prevent the involvement of young people in crime[A20]' (??). In this agreement, each school was linked to local police stations and local reporting systems on school-based crime and violence were established. Safe School Committees were also established that worked in partnership with local non-governmental organisations, local police, and district officials to implement crime prevention programmes in schools and community mobilisation interventions. This was followed by the initiation of the National School Violence Prevention Framework (NSVPF) in 2013 that sought to integrate existing school safety strategies and policies and provide a simplistic, yet comprehensive, approach to addressing the violence prevention needs of schools. The framework outlined roles and responsibilities of the DBE, provincial departments of education, and schools and school communities, and stipulated that provincial departments ensure that all schools were trained and 
Social Cohesion, Violence, and Education in South Africa

implemented the framework, ensured a reporting system that linked school to national, and ensured that school-level role players were properly equipped to deal with the challenges related to safety. The framework included practical manuals for the diagnosis and identification of problems, with actual dealings and interventions planned according to the specific situations of schools.

And as is clear from the above, by prioritising the physical manifestations of violence to the neglect of addressing other normalised and symbolic forms of violence in schools, policies after 2008 tended to securitise violence and, in so doing, closed down opportunities for alternative social cohesion initiatives to gain traction in schools. This is most evident in schools where legalistic support was provided to learners to protect them from violence at schools, but were not followed by the necessary capacity of school governing bodies and provincial departments to implement school safety measures nor to ensure safe learning environments for teachers and learners. There was also an absence of the necessary resources, skills and training for school governing bodies and teachers to fulfil their duties (Squelch, 2001).

We contend that by focusing mainly on the physical dimensions of violence, and not adequately attending to the needs of victims of school-based violence, schooling policies have in fact contributed to the escalation of violence in schools. It is an added drawback that it is mostly learners in impoverished areas, where there are high levels of violence and little resources available to deal with it, that suffer as a result of this approach. 


\section{Teachers and Violence}

A further challenge to social cohesion in South African schools, that has strengthened the resolve of the above security-framed approach, has been the level of sexual abuse of learners by educators, and the large numbers of inappropriate relationships between educators and learners. According to the above-cited study of CJCP in $2013,4.7 \%$ of secondary school learners were sexually assaulted or raped while at school in the 12-month period. It also found that female learners (7.6\%) were more prone to be victims of sexual assault than their male counterparts $(1.4 \%)$, and that a great number of learners were re-victimised. The extent of the abuse has placed enormous pressure on government policy since 1994, given that it is government that is accountable for what happens to learners in schools, and given that teachers are meant to be the legal and moral arbiters of the state's In Loco Parentis Responsibility.

Policies such as the Employment of Educators Act (1998), [A21]that regulates the conditions of service, discipline, retirement and discharge of educators, have focused on developing better processes that force provincial departments of education to dismiss educators found guilty of committing acts of sexual assault on learners, or for having a sexual relationship with a learner of the school where he or she was employed. It is expected in new amendments that the South African Council for Educators Act (2000) would further assist by ensuring that an educator is removed from the $\mathrm{SACE}_{[\mathrm{A} 22]}$ register if he or she was "found guilty of a breach of the code of professional ethics" (??[A23]). The SACE Code of Professional Ethics outlines the conduct that is expected between educators and learners, namely that educators have to refrain from "any form of abuse (section 3.5)", "improper physical contact with learners (section 3.6)", "sexual harassment 
Social Cohesion, Violence, and Education in South Africa

(physical or otherwise) of learners (section 3.8)", and "any form of sexual relationship with learners at any school (section 3.9)" (??[A24]).

On the side of learner rights, the Criminal Law (Sexual Offences and Related Matters) Amendment Act (2007, section 54) and the Children's Act (2005, section 1) have also attempted to put better processes in place to deal with the problem, such as making it a crime for an educator to fail to report a sexual offense against a child, especially if that educator knows or reasonably believed that a child was being sexually abused.

Again, notwithstanding the policies and processes noted above, the over-emphasis of a legal framework approach has meant that teachers and schools have invariably not been able to tackle the other dimensions of sexual violence that linger within schools, nor insert an approach that engages with the root of the phenomenon. These efforts have also not been helped by most educators who sexually abuse learners not facing meaningful consequences for their actions, nor government departments not being held accountable for their failure to protect, prevent and respond to such abuse (University of Witwatersrand, 2014).

\section{Teachers, Social Cohesion, and Social Justice}

If the goal of social cohesion is to develop a bond that brings individuals together and influences their behaviour (Shuayb 2012), how can state policies best realise this? If social cohesion initiatives are meant to generate feelings of trust, a common sense of belonging, and a willingness to cooperate with others in contexts of social justice, how can policies address the kinds of structural issues and factors that perpetuate inequalities and increase disunity? A key challenge in 
Social Cohesion, Violence, and Education in South Africa

the above regard is how to simultaneously address the micro issues of teacher and learner protection and the macro-level challenge of tackling the social, cultural, and political conditions that contribute to unequal distribution within society. Social cohesion initiatives can only provide social meaning and respect for all citizens when policies ensure the kinds of participation that puts everyone on par with each other as full partners in social interaction (Fraser, 2005).

Part of the solution, we imagine, lies in how different kinds of violence are identified and addressed within the schooling lives of teachers and learners, and how these are addressed in meaningful ways through the explicit and hidden curriculum. Social cohesion initiatives will only be able to contribute to forms of positive peace in schools, and provide the kinds of social justice necessary to transform the root causes of violence in schools, when there is meaningful schooling participation and when "marginalised learners" start achieving better schooling outcomes (Keddie, 2012, p. 15). In that regard, the recent focus in the 2030 global education and development [A25]on generating quality has rightly emphasised a concern with teachers, teaching and teacher education. Emphasising the role of teachers in fostering social cohesion will go a long way towards creating the schooling environments required to achieve this. The policy recommendations in the UNESCO Position Paper on Education post-2015 (UNESCO, 2014), for example, suggest a range of key aspects regarding teachers, including[A26]: a) recruiting and retaining well-trained and motivated teachers who use inclusive, gender-responsive, and participatory pedagogical approaches to ensure effective learning outcomes; b) providing content that is relevant to all learners and to the context in which they live; c) establishing learning environments that are safe, gender-responsive, inclusive and conducive to learning, and encompass mother tongue-based multilingual education; d) ensuring that learners reach sufficient levels of knowledge and competencies according to 
Social Cohesion, Violence, and Education in South Africa

national standards at each level; e) strengthening capacities for learners to be innovative and creative, and to assimilate change in their society and the workplace and over their lifespans; and f) strengthening the ways education contributes to peace, responsible citizenship, sustainable development and intercultural dialogue. (p.8).

However, whilst teachers are obviously important, there is an added need to develop a contextualised and clear understanding of what pedagogical processes are needed in schools to generate the kind of quality learning that is able to effect social solidarity and change. This also applies to how teacher agency is understood with regard to teachers working with learners in creative and dynamic ways. A contextualised reading of teacher agency is crucial, as Fenstermacher and Richardson (2005) note:

There[A27] is currently a considerable focus on quality teaching, much of it rooted in the presumption that the improvement of teaching is a key element in improving student learning. We believe that this policy focus rests on a naive conception of the relationship between teaching and learning. This conception treats the relationship as a straightforward causal connection, such that it could be effective, it could be sustained under almost any condition, including poverty, vast linguistic, racial or cultural differences (p.205).

In current policy texts, teacher agency is often reduced to a variety of audit trails that underplays their ability to enact generative learning in classrooms with pupils (Robertson, 2012). Thus, in terms of what roles teachers could play in relation to social cohesion, this chapter concludes with 
three key viewpoints. First, we point out that there are currently far too many expectations being placed on teachers. They have to engage with transferring subject knowledge, life skills, citizenship and peace education, moral and ethical education, child protection, human rights, skills for sustainable livelihoods, challenging gender inequalities, and the practice of learnercenteredness, to name but a few (Sinclair, 2002; UNESCO, 2006). While these are important dimensions in the lives of learners and schools, such an ambitious variety of responsibilities runs the real risk of overstating the potential of schools and their teachers to effect broad social transformation. Davies (2010, p. 496) has warned against "over-optimism about education's impact on society" and, as this chapter argues, teachers. In this context, it is sobering to note that in a survey of ten countries, only $23 \%$ of teachers thought they had influence over policy and practice (UNESCO, 2013). As such, teacher agency is not a realistic possibility, nor is agency possible, when faced with multiple and conflicting demands in environments focused on narrow accountability measures. Second, we argue that the current trend to focus teacher energies on mainly knowledge and content needs to be rebalanced to accommodate firmer relationships with learners and the communities from which they come. In recent times, the responsibility for assisting learners to deal with their emotional or psychological)] everyday challenges been shifted to civil society organisations. This location of crucial services outside of schools seriously undermines the kinds of social relationships between learners and teachers that are required for social cohesion initiatives to gain traction in schools. Lastly, teachers cannot be expected to be change agents in schools if their capacities to engage in social cohesion initiatives continue to be constrained by the approaches of policies, the ways in which policies conceptualise key concepts (like violence) that shape school environments, and the structures with which they interact. Social cohesion initiatives must recognise that the roles and lives of teachers are firmly interconnected 
within the broader networks of relationships and structures in which they participate, and that teachers can only play productive roles within these networks of relationships if the policies and violence that define their everyday life are better problematised.

The actions proposed above are only possible in the South African context by ensuring that the education policy landscape foregrounds a more transformative understanding of social cohesion, that teacher education providers and others involved in teacher professional development offer an enriched learning experience for trainee and practicing teachers to capacitate them to act as agents of social cohesion, and that public schools and their governance mechanisms and procedures are (re)designed such that they can create a positive environment for redressing inequity and effecting social cohesion. Only by these changes and more, can South Africa overcome the deep historic and structural inequities of a society fractured along the fault lines of race, class, and gender to create the conditions for just and durable peace and social cohesion. 
Social Cohesion, Violence, and Education in South Africa

\section{References}

Abrahams, N. (2004). Sexual violence against women in South Africa. Sexuality in Africa Magazine, 1(3), 4-6.

Auyero, J., Bourgois, P., \& Scheper-Hughes, N. (2015). Violence at the urban margins. New York, NY, USA: Oxford Univesity Press. NOT IN TEXT

Barrett, A. M., Chawla-Duggan, R., Lowe, J., Nikel, J., \& Ukpo, E. (2006). The concept of quality in education: A review of the "international" literature on the concept of quality in education. England: EdQual. Retrieved from http://tct-test-referencematerials.yolasite.com/resources/Educational\%20Quality\%20Assurance.pdf

Bellah, RN. (1973). Emile Durkheim on morality and society. Chicago, IL, USA: University of Chicago Press.

Bentham, J. (1780). 1988 (WHAT IS THE YEAR OF PUBLICATION?) The principles of morals and legislation. Amherst, NY, USA: Prometheus Books.

Buckland, P (2005). Reshaping the future: Education and postconflict reconstruction. World Bank Publications. Retrieved from https://books.google.co.za/books?hl=en\&lr=\&id=fJoKm7DjDFEC\&oi=fnd\&pg=PR9\&d $\mathrm{q}=$ Reshaping+the+Future:+Education+and+Postconflict+Reconstruction\&ots=mgOjzo7 wiJ\&sig=TRIfd_407iohc42xcjGuhKQ4U-E

Burton, P., \& Leoschut, L. (2013). School violence in South Africa. Retrieved from http://www.fedsas.org.za/downloads/15_18_12_Monograph12-School-violence-inSouth\%20Africa.pdf 
Social Cohesion, Violence, and Education in South Africa

Chan, J., To, H.P., \& Chan, E. (2006). Reconsidering social cohesion: Developing a definition and analytical framework for empirical research. Social Indicators Research, 75(2), 273 302.

DAC. (2012). A National Strategy for Developing an Inclusive and a Cohesive South African Society. Republic of South Africa. SOURCE?

Davies, L. (2010). The different faces of education in conflict. Development, 53(4), 491-497.

DoE. (2001). Manifesto on values, education and democracy. SOURCE?

Durkheim, E. (1964). The division of labor in society. New York, NY, USA: The Free Press.

Feinberg, W., \& Soltis, JF. (2009). School and society. New York, NY, USA: Teacher College Press.

Fenstermacher, G., \& Richardson, V. (2005). On making determinations of quality in teaching. The Teachers College Record, 107(1), 186-213.

Fraser, N. (1995). From redistribution to recognition? Dilemmas of justice in a 'post-socialist' age. New Left Review, 68-68. NOT CLEAR WHAT THIS IS (68-68); ALSO INSERT VOL/ISSUE NUMBERS?

Fraser, N. (2005). Reframing justice in a globalizing world. New Left Review, 36, 79-88.

Freemantle, I. (2012). Addressing the division of whom? South Africa's "fault lines" and Trends in social cohesion policy. African Centre for Migration \& Society. REFERENCE IS INCOMPLETE.

Friedkin, N. E. (2004). Social cohesion. Annual Review of Sociology, 30, 409-425.

Friedman, M. (1962). Capitalism and freedom. Chicago, IL, USA: University of Chicago Press. 
Social Cohesion, Violence, and Education in South Africa

Galtung, J. (1976). Three approaches to peace: Peacekeeping, peacemaking and peacebuilding. In J. Galtung \& C. Ejlers (Eds.), Peace, war and defence: Essays in peace research (pp. 282-304). California, CA, USA: Copenhagen.

Green, A., \& Janmaat, J. G. (2011). Regimes of social cohesion: Societies and the crisis of globalization. Palgrave Macmillan. Retrieved from http://eprints.ioe.ac.uk/16188/

Hamber, B. (2007). Forgiveness and reconciliation: Paradise lost or pragmatism? Peace and Conflict, 13(1), 115-125.

Hamber, B., \& Kelly, G. (2004). A working definition of reconciliation. Occasional Paper Published by Democratic Dialogue, Belfast. Retrieved from http://www.ark.ac.uk/orb/summaries/Hamber04.doc

Hayek, F. A. (1944). The Road to serfdom, London, George Routledge \& Sons. Chicago, IL, USA: University of Chicago Press.

Keddie, A. (2012). Schooling and social justice through the lenses of Nancy Fraser. Critical Studies in Education, 53(3), 263-279.

Marc, A., Willman, A., Aslam, G., Rebosio, M., \& Balasuriy, K. (2012). Societal dynamics and fragility: Engaging societies in responding to fragile situations. Washington, DC, USA: World Bank Publications.

McCandless, E. (2011). Peace dividends and beyond: Contributions of administrative and social services to peacebuilding. United Nations Thematic Review for the Peacebuilding Support Office, New York. PLEASE CHECK THIS REFERENCE AND AMEND

Merton, R.K. (1968). Social theory and social structure. New York, NY: Free Press.

Mncube, V., \& Harber, C. (2013). The dynamics of violence in South African schools. Pretoria, South Africa: University of South Africa. 
Social Cohesion, Violence, and Education in South Africa

Mourshed, M., Chijioke, C., \& Barber, M. (2010). How the world's most improved school systems keep getting better. McKinsey London. PLEASE FIX REFERENCE

Novelli, M., Lopes Cardozo, M., \& Smith, A. (2014). A theoretical framework for analysing the contribution of education to sustainable peacebuilding: 4rs in conflict-affected contexts. Retrieved from http://learningforpeace.unicef.org/wpcontent/uploads/2015/05/Theoretical-Framework-Jan15.pdf

Organization for Economic Cooperation and Development (OECD). (2011). Perspectives on Global Development 2012: Social cohesion in a shifting world. Paris, France: OECD Publishing.

Osler, A. (2011). Education policy, social cohesion, and citizenship. In P. Ratcliffe \& I. Newman (Eds.), Promoting social cohesion: Implications for policy and evaluation (pp. ?? INSERT PAGE NUMBERS HERE). Bristol, England: Policy Press.

Parsons, T. (1967). The structure of social action, volume 1: Marshall, Pareto, Durkheim 2nd Edition. New York, NY, USA: Free Press.

Robertson, S. L. (2012). Placing teachers in global governance agendas. Comparative Education Review, 56(4), 584-607.

Rose, P., \& Greeley, M. (2006). Education in fragile states: Capturing lessons and identifying good practice. Draft Paper Prepared for the Development Assistance Committee Fragile States Working Groups, Service Delivery Workstream, Subteam for Education Services. Retrieved from http://toolkit.ineesite.org/resources/ineecms/uploads/1096/Educ_Fragile_States_Capturin g_Lessons.PDF 
Social Cohesion, Violence, and Education in South Africa

Salmi, J. (2000). Violence, democracy, and education: An analytic framework. PROMOTINGLCSHD Paper Series, 56.

Sayed, Y., \& Ahmed, R. (2015). Education quality, and teaching and learning in the post-2015 education agenda. International Journal of Educational Development, 40, 330-338.

Sayed, Y., Kanjee, A., \& Nkomo, M. (2013). The search for quality education in post-apartheid South Africa. CITY, South Africa: HSRC Press.

Scheper-Hughes, N., \& Bourgois, P. (2004). Violence in war and peace: An anthology. Oxford, England: Blackwell Publishing.

Seitz, K. (2004). Education and conflict: The role of education in the creation, prevention and resolution of societal crises-consequences for development cooperation. Deutsche Gesellschaft für Technische Zusammenarbeit (GTZ). INCOMPLETE REFERENCE (RETRIEVED FROM ??)

Shuayb, M. (Ed.) (2012). Rethinking education for social cohesion: International case studies. Basingstoke, COUNTRY: Palgrave McMillan.

Sinclair, M. (2002). Planning education in and after emergencies. UNESCO, International Institute for Educational Planning Paris. Retrieved from http://toolkit.ineesite.org/resources/ineecms/uploads/1091/Planning_Education_in_and_A fter_Emergencies_EN.pdf

Smith, A., McCandless, E., Paulson, J., \& Wheaton, W. (2011). The role of education in peacebuilding: Literature review. New York, NY, USA: UNICEF.

Squelch, J. (2001). Do school governing bodies have a duty to create safe schools? An education law perspective: current issues in education law and policy. Perspectives in Education: 
Social Cohesion, Violence, and Education in South Africa

Education Law and Policy in South Africa: Special Issue 4, 19,-137 (PLEASE CHECK THIS AND AMEND SO VOLUME, ISSUE AND PAGE NUMBERS ARE CLEAR).

Tawil, S. \& Harley, A. (2004). Education, conflict, and social cohesion. Geneva, Switzerland: UNESCO, International Bureau of Education.

Tikly, L., \& Barrett, A. M. (2011). Social justice, capabilities and the quality of education in low income countries. International Journal of Educational Development, 31(1), 3-14.

UNESCO. (2013). Education for All Global Monitoring Report 2013/4 Teaching and Learning: Achieving Quality for All. Paris, France: UNESCO.

UNESCO. (2014). Position Paper on Education Post-2015. INCOMPLETE REFERENCE

UNESCO, IIEP. (2006). Guidebook for planning education in emergencies and reconstruction. Paris, France: UNESCO International Institute for Educational Planning.

University of Witwatersrand. Centre for Applied Legal Studies, Cornell Law School. Avon Global Center for Women and Justice, \& Cornell Law School. International Human Rights Clinic. (2014). Sexual Violence by educators in South African schools: Gaps in accountability. Avon Global Center for Women and Justice and Dorothea S. Clarke Program in Feminist Jurisprudence. INCOMPLETE REFERENCE

Zwarteveen, M. Z., \& Boelens, R. (2014). Defining, researching and struggling for water justice: some conceptual building blocks for research and action. Water International, 39(2), 143158. 